\title{
Ciência e violência nas imagens do transporte do meteorito do Bendegó para o Rio de Janeiro (1887-1888)
}

Science and violence in images of the transportation of the Bendegó meteorite to Rio de Janeiro (1887-1888)

DOI: 10.20396/rhac.v2i2.15464

\author{
LETI SQUEFF \\ Departamento de História da Arte - EFLCH/Unifesp-Brasil \\ (iD 0000-0002-2704-8819
}

\section{Resumo}

Em 1887 foi organizada uma expedição para trazer o meteorito chamado "do Bendegó" da Bahia para o Rio de Janeiro. A operação envolveu enorme logística para transportar a pedra de mais de 5 toneladas. Neste artigo, pretendo investigar como ciência e política se articulam nas fotografias do meteorito do Bendegó. Elas tiveram papel central na construção de um imaginário que vinculava a "posse" do meteorito à ciência, e assim, participavam da criação de uma imagem civilizada e "científica" para o Império brasileiro. Por outro lado, também a violência da escravidão transparece nas imagens associadas ao meteorito.

Palavras-chave: Meteorito do Bendegó. Cultura visual. Fotografia. Escravidão. Representação do território. Pintura de paisagem.

\begin{abstract}
In 1887 an expedition was organized to bring the meteorite known as "do Bendegó" from Bahia to Rio de Janeiro. The mission involved enormous logistics to transport the $5+$ ton stone to Rio de Janeiro. In this article, I intend to explore how science and politics are articulated in the photographs of the Bendegó meteorite. They played a central role in the construction of an imaginary that associated the "possession" of the meteorite with science, and thus, contributed to the creation of a civilized and "scientific" image for the Brazilian Empire. On the other hand, the violence of slavery also emerges in the images associated with the meteorite.
\end{abstract}

Keywords: Bendegó meteorite. Visual culture. Photography. Slavery. Representation of the territory. Landscape painting. 
Em 2018 o Museu Nacional do Rio de Janeiro pegou fogo, destruindo um acervo de vinte milhões de objetos. No dia seguinte, nas buscas, uma descoberta: pelo menos uma peça havia sido salva. O meteorito conhecido como "Bendegó", um enorme bloco de ferro, resistira às chamas. A imagem do meteorito intacto no meio dos destroços circulou em jornais de todo o mundo. Vista desde a perspectiva de 2021, a destruição do museu parece quase um presságio do que veio a seguir: o radical corte de verbas para cultura e ciência no Brasil, a pandemia que se abateu sobre o país, agravada por políticas de Estado negacionistas e necrófilas.

Talvez em nenhum momento da história a relação entre política e ciência tenha ficado tão clara quanto agora. O uso de medicamentos para uso preventivo, o chamado Kit COVID, a disputa entre nações e empresas internacionais pela fabricação da vacina, bem como a distribuição desigual da mesma pelas nações do planeta são indícios da necessidade de se problematizar as relações entre ciência e política. Este é um problema que fundamenta o presente artigo.

Neste texto, pretendo investigar como ciência e política se articulam nas imagens do meteorito do Bendegó. De fato, em 1888, além dos debates sobre a abolição, um outro assunto chamou fortemente a atenção do público: o meteorito do Bendegó. A chegada do meteorito ao Rio de Janeiro foi vista como ápice do processo de construção de um saber científico sobre o país. Processo que vinha sendo promovido pelo governo imperial e pelos "homens de ciência" desde meados do século, com a criação de instituições como o Instituto Histórico e Geográfico Brasileiro, no apoio do imperador a artistas, revistas literárias, livros, além de expedições organizadas por estrangeiros e também por cientistas que atuavam no Brasil.

O meteorito do Bendegó fez parte do último esforço científico e cultural do Império. O álbum da expedição organizada para levar o meteorito para o Rio de Janeiro, e a divulgação da imagem do Bendegó na cena internacional - que ocorreu de diversas formas, mas teve na exposição universal de Paris de 1889 um momento marcante - eram, por um lado, parte de um mesmo todo que se articulava à tradição das expedições científicas do século XIX, e, por outro, a um projeto de construção de uma imagem civilizada e "científica" para o Império brasileiro.

Nas páginas seguintes, irei discutir, em primeiro lugar, como o meteorito tornou-se um assunto de interesse "científico", mobilizando não apenas os engenheiros e políticos do império, mas também uma grande parcela da população, cuja curiosidade sobre o meteorito seria alavancada pela imprensa. Em segundo lugar, discutirei as fotografias da expedição, que foram incluídas no relatório de viagem, expostas para visitação, reproduzidas em revistas, enviadas para sábios estrangeiros, entre outros. Estas imagens tiveram um importante papel na construção de uma opinião a respeito do meteorito, bem como sobre o "feito" dos engenheiros. Além disso, e sobretudo, essas imagens tiveram papel central na construção de um imaginário associando a "posse" do meteorito à ciência, e esta, ao estado imperial. Como se sabe, o 
pensamento científico se insere em uma situação política, econômica e social específica- é histórica e socialmente constituído'. Desse ponto de vista, faz sentido discutir os usos políticos de imagens científicas, ou o uso político das "descobertas" da ciência.

\section{Por que o meteorito do Bendegó?}

A expedição para trazer o meteorito do Bendegó da Bahia saiu do Rio de Janeiro em 20 de agosto de 1887. O meteorito se tornaria um assunto comum nos jornais a partir de então. Alguns jornais davam notícias periódicas da viagem da Comissão, informando o público do Rio de Janeiro sobre o andamento do transporte da pedra sideral para a cidade. "Exporemos hoje em nosso escritório duas fotografias representando o famoso metereólitho do Bendegó e a turma de engenheiros e operários que tomaram parte no serviço do último dia de trabalho", estampava, já em 11 de outubro, orgulhosamente O Paiz. ${ }^{2}$ Com o passar dos meses, a palavra Bendegó deu nome a muitas iniciativas pela cidade. Músicos lançaram o "tango do Bendegó”, e o sucesso foi tanto que, pouco tempo depois, lançaram também a "polka do Bendegó" ${ }^{4}$. No carnaval de 1889, moradores reclamaram do "baile público" Bendegó, porque os foliões bebiam demais e promoviam arruaças 5 . Um teatro da cidade abriu o espetáculo "Bendegó", que trazia vários números de dança e cenas cômicas sobre os costumes da cidade, com enorme sucesso. "É o Bendegó" tornou-se expressão comum nas notícias políticas da cidade 7 . A imprensa funcionou como uma espécie de divulgadora da Comissão do Bendegó, criando um clima de opinião sobre a grande realização científica que seria alcançada em breve, graças ao trabalho dos engenheiros. Até agora foram localizados cerca de sessenta artigos a respeito do meteorito. ${ }^{8}$

A primeira questão que surge da leitura de jornais e revistas da época é justamente essa. Por que um meteorito? Para trazer o meteorito do Bendegó da região de Monte Santo até a estrada de ferro mais próxima, a comitiva percorreu $113 \mathrm{~km}$ em 126 dias. A lentidão da travessia- que avançava pouco menos de um

\footnotetext{
${ }^{1}$ RIEZNICK, Marina; LOIS, Carla. Micrografías interrogadas. Una aproximación a la cuestión de las imágenes técnicas en la historia de las ciencias en la Argentina (siglos XIX y XX). Caiana, Revista de Historia del Arte y Cultura Visual del Centro Argentino de Investigadores d Arte (CAIA) 12, jan./jul. 2018, p. 1-17. Disponível em: http://caiana.caia.org.ar/resources/uploads/12pdf/Caiana_12L_Rieznik\%20y\%2oLois.pdf. Acesso em: 20 mar. 2021.

${ }^{2}$ Meteorolitho de Bendegó, O Paiz, terça-feira, 11 out. 1887, p. 1.

${ }^{3}$ Tango do Bendegó. Jornal do Commercio. 17 jan. 1889.

${ }^{4}$ O Bendegó- Polka da Actualidade, de Abdon Milanez. Jornal do Commercio, n. 215, 3 ago. 1888

${ }^{5}$ Vizinhança incomodada, Jornal do Commercio, n. 79, 20 mar. 1889

${ }^{6}$ A Revista O Bendegó faz muitas apresentações na cidade, com grande sucesso. Jornal Do Commercio, 3 abr. 1889.

${ }^{7}$ Crônica política se refere a um dos projetos do governo de "Um Bendegó" de tão pesado. Cf. Assembleia Geral, de 10 de julho de 1888, Jornal do Commercio, n. 192, 11 jul. 1888. Bendegó é o nome de um dos cavalos que corre no Derby Club. Jornal do Commercio, 6 ago. 1888

${ }^{8}$ Alguns dos jornais consultados: Jornal do Commercio, O mequetrefe, Revista de Engenharia, Novidades, Gazeta da Tarde, 0 Paiz, Revista llustrada, para o período entre 1886 e 1889.
} 
quilômetro por dia- explica-se pelas dimensões de empreitada: a massa de ferro de 5 toneladas era arrastada num carretão feito especialmente para transportá-la, puxado por 24 bois na maior parte da viagem.

A maioria dos relatos afirma que o meteorito do Bendegó foi encontrado em 1785 no interior da Bahia. Houve uma primeira tentativa de remoção, por ordem da coroa portuguesa, que queria mandá-la para Lisboa. A tentativa malogrou, e a pedra, que rolou da carroça que a transportava, caiu no rio Bendegó 9 . Em 1810, o francês Aristides F. Mornay (1779 - 1855), em viagem comissionada pelo Covernador Geral da Bahia para estudar fontes minerais, foi até Monte Santo e reconheceu a pedra como sendo de fato um meteorito, composto por ferro metálico. Depois disso, vários naturalistas europeus, viajando pelo império do Brasil, descreveram-no. Caso de Spix e Martius, que levaram pedaços do meteorito para Viena e discorreram sobre ele na Reise in Brasilien (1823-1831). Mais tarde, Charles F. Hartt faria muitas considerações sobre o "metereólitho" em seu relato Thayer Expedition: scientific results of a journey in Brazil (1870) ${ }^{10}$. Percebe-se, assim, que notícias sobre o meteorito circularam nos meios dos naturalistas e geólogos durante todo o século.

O Bendegó foi finalmente trazido do sertão baiano para o Rio de Janeiro, em uma empreitada cara e demorada. As obras de remoção começaram em 7 de setembro de 1887 e só terminaram em 15 de junho de 1888, com a chegada da missão ao Rio de Janeiro. A enorme massa de metal foi arrastada sobre montanhas, serras e rios até a estação ferroviária mais próxima. De lá, o meteorito foi levado para Salvador, puxado por um trem, em um percurso de 363 quilômetros. Um barco a vapor finalmente levou-o para o Rio de Janeiro. Ao chegar ao porto do Rio de Janeiro, o meteorito ficou exposto, inicialmente, no arsenal da Marinha, onde foi visto por diversas autoridades do império. A seguir, a massa de ferro foi exposta à curiosidade do público na Praça de São Francisco. As pessoas queriam ver e tocar aquela maravilha que havia caído do céu. O número de espectadores foi tão grande que um grupo de oficiais foi designado para "vigiar" a pedra à noite ${ }^{11}$. Em 27 de novembro de 1888, o Bendegó foi finalmente entregue ao Museu Nacional, quando foi lavrado o "Certificado de Recebimento do Meteorito de Bendegó no Museu Nacional do Rio de Janeiro"12.

Por que uma massa de ferro enorme, que ainda por cima estava a centenas de quilômetros de distância do Rio de Janeiro, despertou tanta atenção? A resposta é complexa, e inclui a circulação de informações sobre o meteorito nos meios científicos internacionais, além do fortalecimento de instituições de pesquisa e divulgação científica no Império. Finalmente, interesses econômicos também parecem ter motivado a empreitada.

\footnotetext{
${ }^{9}$ CARVALHO, Wilton Pinto de et al. O Meteorito Bendegó: história, mineralogia e classificação química. Revista Brasileira de Geociências, v. 41, n. 1, 2011, p. 141-156.

${ }^{10}$ HARTT, Charles Frederick. Thayer Expedition: scientific results of a journey in Brazil, by Louis Agassiz and his companions. Ceology and physical Ceography of Brazil. Boston: Fields, Osgood \& Co, 1870.

${ }^{11}$ O Bendegó. Jornal Novidades. 27 nov. 1888, p. 1.

${ }^{12}$ Cf. Meteorito de Bendegó, Revista de Engenharia, 1888, n. 200, p. 263
} 


\section{O meteorito e os interesses do império}

A comissão encarregada de buscar o meteorito era formada por três engenheiros, sendo chefiada por José Carlos de Carvalho. ${ }^{13}$. No entanto, muitas pessoas se envolveram no projeto de levar o meteorito para o Rio de Janeiro. Além dos engenheiros citados, deve-se incluir outros personagens: o imperador d. Pedro Il; a princesa regente d. Isabel; e o astrônomo belga Luís Cruls, diretor do Observatório Astronômico do Rio de Janeiro, só para citar os mais conhecidos.

Vale destacar aqui a atuação do geólogo norte-americano Orville Derby, que na época era diretor da seção de mineralogia do Museu Nacional. Derby foi, ao que tudo indica, o grande articulador, o primeiro a aventar a hipótese de trazer o meteorito para o Rio de Janeiro ${ }^{14}$. Como mineralogista, ele acompanhara os trabalhos tanto da Comissão Ceológica do Império quanto da Comissão Hidrográfica para Estudos do Rio São Francisco. Em alguma dessas viagens, em que passou mais de uma vez pela Bahia, Derby talvez tenha ouvido falar do meteorito, pois já em 1883, ele solicita informações sobre o meteorito de um outro engenheiro, o baiano Theodoro Sampaio, e inicia um movimento para trazer a pedra sideral para o Museu Nacional'5.

Duas instituições se articularam para a organização da expedição: o Museu Nacional e a Sociedade de Geografia do Rio de Janeiro. Entre uma instituição e outra, houve a circulação de engenheiros, naturalistas, políticos e o próprio imperador, que atuariam para concretizar a intenção de retirar o meteorito da natureza e instalá-lo no que aqueles homens consideravam seu lugar de direito- o museu. Desde 1868 subordinado ao Ministério da Agricultura, Comércio e Obras Públicas, o museu buscava assumir seu lugar entre as instituições internacionais de pesquisa. Como o segundo maior meteorito do mundo, na época, e o maior jamais colocado em um museu, o Bendegó parecia uma aquisição importante para o Museu Nacional, capaz de chamar a atenção de cientistas de todo o mundo ${ }^{16}$.

\footnotetext{
${ }^{13}$ A "Comissão Encarregada da Remoção do Meteorito do Bendegó para o Museu Nacional" era formada por: José Carlos de Carvalho (1847-1934) (engenheiro naval, ex-oficial da Marinha na Guerra do Paraguai), Vicente José de Carvalho Filho (?-1915) (engenheiro civil) e Humberto Saraiva Antunes (engenheiro civil)

${ }^{14}$ LOPES, Maria Margaret, O Brasil descobre a pesquisa científica: os museus e as ciências naturais no século XIX. São Paulo: Editora Hucitec, 1997, p. 178. BRACA, Jezulino. A pedra que veio lá do infinito: o meteorito de Bendegó e o Museu Nacional, Concinnitas, v. 34, 2018, p. 147-164.

15 Tosatto afirma que após falecimento de Hartt, em 1878, Derby fica sem emprego, período em que trabalha para "um particular" em excursão, entre outras, pela "bacia do rio São Francisco". Também atua na Comissão Hidráulica do Império, chefiada por outro engenheiro norte-americano, em que faz "importante viagem exploratória ao rio São Francisco" junto com Theodoro Sampaio. O autor não menciona, portanto, a comissão citada por Lopes. TOSATTO, Pierluigi, Orville A. Derby: o pai da geologia no Brasil. Rio de Janeiro: CPRM;DNPM, 2001.

${ }^{16}$ CUALTIERI, Regina C., O evolucionismo na produção científica do Museu Nacional do Rio de Janeiro (1876-1915). In: A recepção do darwinismo no Brasil. Rio de Janeiro: Fiocruz, 2003
} 


\section{A fotografia e a pintura paisagística na representação de Bendegó}

Em 25 de junho de 1888, a Comissão do Bendegó apresentou o relatório da viagem, em solenidade que incluiu, entre os ouvintes: a Princesa Isabel, Conde D’Eu, Rodrigo Augusto da Silva (Ministro da Agricultura), Ladislao Netto, Orville Derby, Vicente José de Carvalho, Visconde de Cavalcanti, entre outros ${ }^{17}$. Impresso em português e francês, e enviado a várias partes do mundo, o relatório trazia diversas informações sobre a região em que o meteorito fora encontrado, reunindo mapas, plantas da cidade, comentários sobre a natureza local e até mesmo sobre os habitantes. O documento também trazia 18 fotografias da expedição. Algumas destas fotos serão nosso principal objeto de análise.

No século XIX, a fotografia, juntamente com outros dispositivos ópticos, tornou-se o grande instrumento de divulgação da ciência e da tecnologia, mudando radicalmente as formas de vere a experiência visual como um todo ${ }^{18}$. A fotografia seria amplamente utilizada, registrando o avanço das ferrovias, o conhecimento do território, o contato com grupos indígenas etc. Turazzi lembra que as "expedições fotográficas" eram caras porque o fotógrafo carregava bagagens enormes e pesadas, e tinha que concluir todo o processo químico in loco. ${ }^{19}$ Porém, a partir de 1880, com a substituição do colódio úmido por "placas secas", a participação dos fotógrafos em expedições tornou-se mais fácil e barata. Existem muitas pesquisas sobre essas "missões fotográficas"20. As fotos da expedição de Bendegó devem ser incluídas neste escopo mais amplo das "expedições fotográficas" do Império.

Vamos começar com a primeira foto do conjunto. Esta é provavelmente a primeira foto conhecida do meteorito [Figura 1]. Percebe-se uma intenção descritiva do fotógrafo: mostrar onde estava o meteorito quando foi encontrado pelos integrantes da comissão: seu lugar no rio, a distância da margem, a vegetação rasteira ao seu redor. Assim, à primeira vista, a imagem tem função documental. No entanto, é construída a partir de um típico jogo poético presente na pintura desde o Renascimento.

\footnotetext{
${ }^{17}$ CARVALHO, José Carlos de. Meteorito de Bendegó - relatório apresentado ao ministerio da agricultura, commercio e obras públicas e a sociedade de geographia do Rio de Janeiro sobre a remoção do meteorito de Bendengó do sertão da provincia da Bahia para o Museu Nacional. Rio de Janeiro: Imprensa Nacional, 1888.

${ }^{18}$ CRARY, J. Técnicas do observador: visão e modernidade no século XIX. Rio de Janeiro: Contraponto, 2012.

19 TURAZZI, M.I. Poses e trejeitos: a fotografia e as exposições na era do espetáculo, 1839/1889. Rio de Janeiro: Funarte / Rocco, 1995.

20 VASQUEZ, Pedro. A fotografia no Império. Rio de Janeiro: Zahar, 2002.
} 


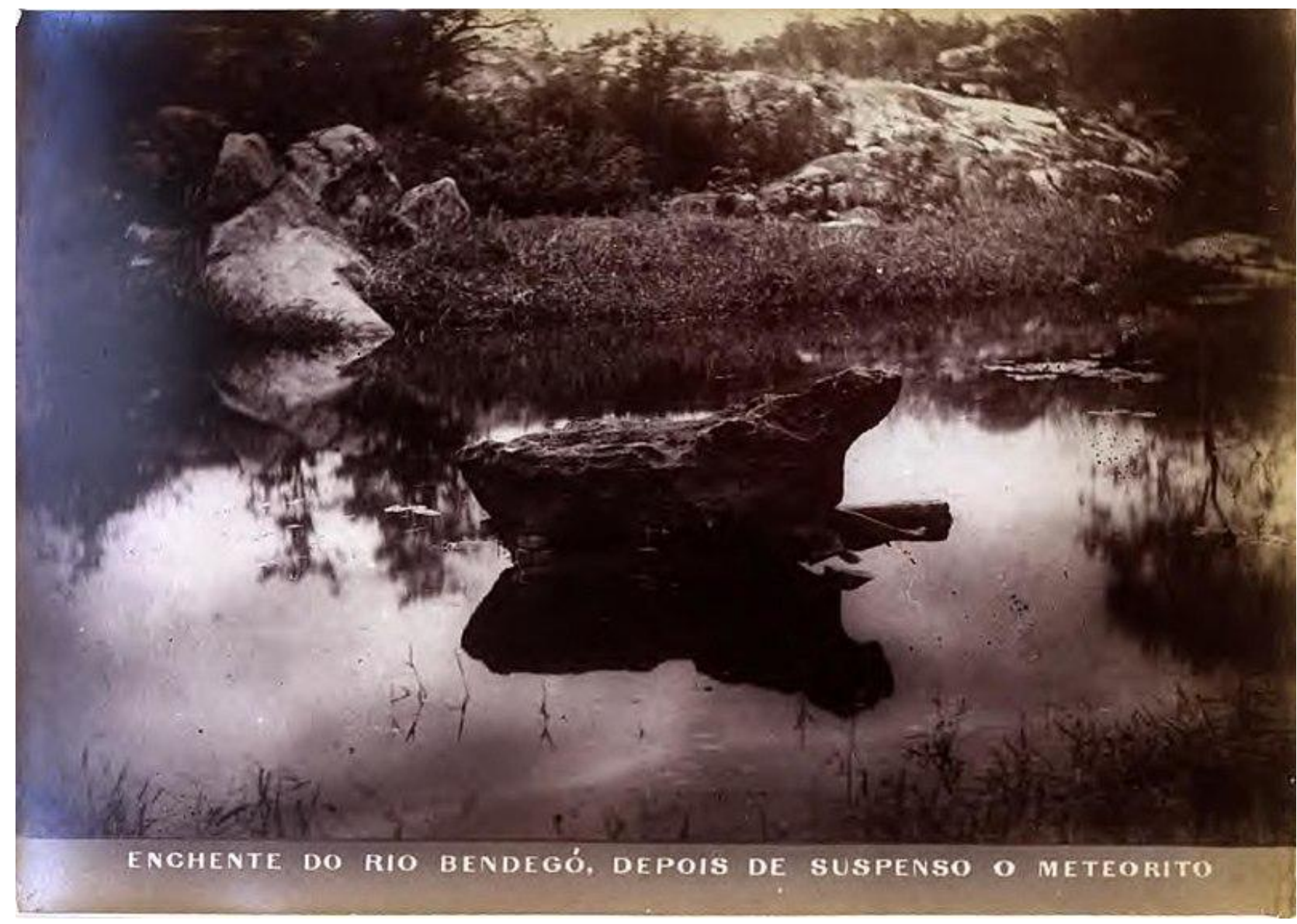

\section{Figura 1:}

Enchente do rio de Bendegó, depois de suspenso o meteorito. In: Meteorito de Bendegó - relatório apresentado ao ministério da agricultura, commercio e obras publicas e a sociedade de geographia do Rio de Janeiro sobre a remoção do meteorito de Bendengó do sertão da provincia da Bahia para o Museu Nacional. Rio de Janeiro: Imprensa Nacional, 1888. Universidade Federal do Rio de Janeiro.

Disponível em: https://bdor.sibi.ufrj.br/bitstream/doc/32/1/bendego-port\%20ocr.pdf. Acesso em: 20 mar. 2021

O meteorito, iluminado por cima, tem sua sombra projetada para a frente. Seu reflexo parece mais escuro e ligeiramente distorcido. A água do rio, como uma espécie de espelho deitado, reflete a luz que vem do céu, criando efeitos tonais e reflexos trêmulos. E aqui, a relação com a pintura de paisagem, ou com a pintura de temática pastoral, sobressaem. Não é do nosso interesse discutir até que ponto as escolhas do fotógrafo foram ou não foram conscientes ou intencionais. O que é interessante é que a imagem do meteorito é o resultado de um esforço para reconstruir, por meio da imagem, todo o ambiente em que o meteorito foi encontrado. Écomo se o meteorito estivesse em sua condição "natural": o rio Bendegó. Nesse sentido, oângulo escolhido pelo fotógrafo chama a atenção. Através de suas lentes, a massa de ferro com mais de 2 metros de comprimento parece um animal se banhando no rio. Como um animal selvagem surpreendido no meio do rio, está no seu "habitat" "natural", formado por um conjunto variado de topografia, flora e também pelo seu 
ambiente. Parece haver nesta fotografia a persistência de um tipo de visualidade típica dos desenhos de campo feitos por pintores naturalistas e botânicos. Neste ponto, é preciso chamar a atenção para as relações entre arte e fotografia no período, questão que tem sido sempre discutida pela bibliografia.

No Rio de Janeiro, a Academia Imperial de Belas Artes teve, desde muito cedo, não só de conviver, mas também de "negociar" com a imagem fotográfica. Em 1855, em suas "Teses para debate", o diretor da instituição, Araújo Porto Alegre, já perguntava: "A fotografia foi útil ou prejudicial à pintura?"21. Alguns anos depois, o pintor Victor Meirelles escreveria o que talvez seja a primeira história da fotografia escrita no Brasil, como assinalou Tadeu Chiarelli, comentando a participação de fotógrafos na II Exposição Nacional de 1866. Nesse contexto, a fotografia e a litografia, que circulam sob a forma de retratos, álbuns de viagens, entre outros, pressionaram os códigos clássicos praticados na Academia do Rio de Janeiro²2.

\section{O meteorito e a bandeira do Império}

Vale a pena discutir outra imagem da expedição - esta amplamente reproduzida em sites e blogs sobre o meteorito. Os engenheiros posam ao lado do meteorito, no $15^{\circ}$ dia da expedição [Figura 2]. A postura orgulhosa dos homens reunidos ao redor da pedra, e da bandeira do Império, colocada no centro da fotografia, sintetiza todo um discurso.

Em suas roupas e botas brilhantes, os engenheiros olham fixamente para a câmera. Eles apoiam os cotovelos no meteorito que, como um animal selvagem subjugado, parece enorme, mas indefeso entre os homens. Além desse grupo principal, os trabalhadores posam ao redor, organizados em pequenos grupos. A distribuição dos personagens torna explícitas relações de hierarquia e subordinação: entre os que planejam o trabalho e aqueles que o realizam com seus corpos. Os que aparecem à direita ainda carregam as varas usadas para controlar os bois usados para arrastar "a besta" de dentro do rio. Próximo ao grupo principal, homens mais bem vestidos sugerem um lugar mais alto na hierarquia. O terreno também foi subjugado pelos engenheiros: está aplanado, e aparecem espalhados alguns utensílios usados pela expedição. Quase no meio da imagem, tremula a bandeira do Império. Colocada logo atrás do meteorito, ela vincula aqueles homens representados no meio de uma paisagem inóspita ao Rio de Janeiro. A bandeira atesta que o feito dos engenheiros é mais um marco do poder do império sobre aquela região distante da corte. O meteorito, colocado no centro da imagem como uma espécie de fera, é o prêmio daqueles homens.

\footnotetext{
${ }^{21}$ A respeito das Teses para Debate, ver: SQUEFF, Letícia, O Brasil nas letras de um pintor: Manuel de Araújo Porto Alegre, $1806-$ 1879. Campinas, SP: Editora da UNICAMP, 2004.

${ }^{22}$ CHIARELLI, T. História Da Arte / História Da Fotografia No Brasil - Século XIX: Algumas Considerações. Ars. [S. I.], v. 3, n. 6, 2005, p. 78-87. Disponível em: https://www.revistas.usp.br/ars/article/view/2943. Acesso em: 20 mar. 2021.
} 


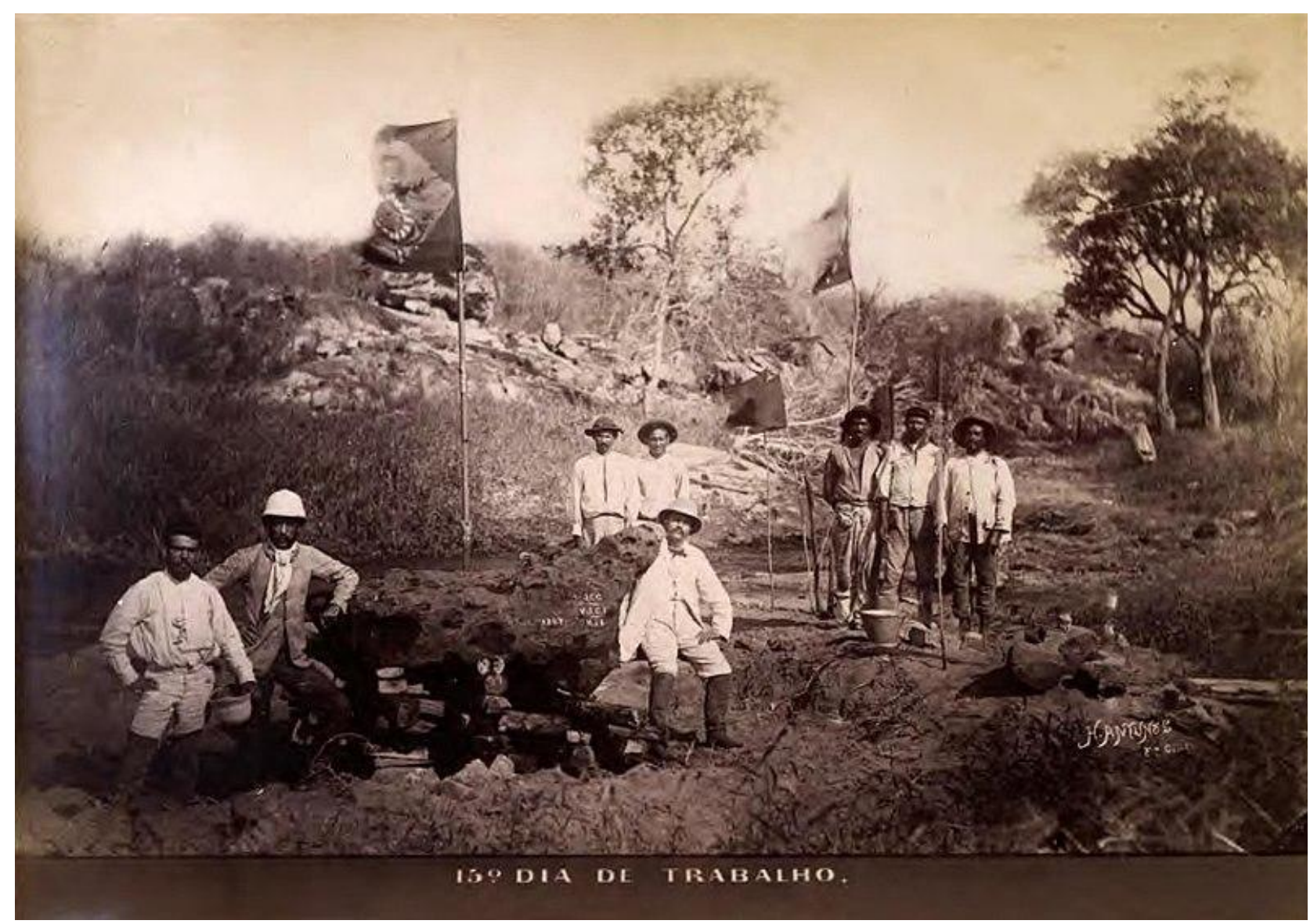

\section{Figura 2:}

$015^{\circ}$ dia de trabalho. In: Meteorito de Bendegó - relatório apresentado ao ministério da agricultura, commercio e obras publicas e a sociedade de geographia do Rio de Janeiro sobre a remoção do meteorito de Bendengó do sertão da provincia da Bahia para o Museu Nacional. Rio de Janeiro: Imprensa Nacional, 1888. Universidade Federal do Rio de Janeiro.

Disponível em: https://bdor.sibi.ufri.br/bitstream/doc/32/1/bendego-port\%20ocr.pdf. Acesso em: 20 mar. 2021.

No repertório de imagens das expedições, esta fotografia poderia ser classificada como "foto de parada" 23. A foto funciona assim como uma espécie de monumento à proeza dos engenheiros, uma prova de que o império civiliza o "sertão", organiza e "limpa" a paisagem e, por fim, "resgata" a natureza para Ciência.

Desse modo, a comissão do Bendegó deve ser entendida dentro de um quadro mais amplo de exploração, apropriação e demarcação do território da nação brasileira. E em todo este processo, a comissão contava com duas "armas", estreitamente vinculadas: a da técnica, que permitiu que o meteorito fosse arrastado com o auxílio de um "carretão" projetado especialmente para esse fim. E a da imagem. Sem a fotografia, o "feito" dos engenheiros, a vitória da técnica sobre a natureza, e, subjacente a ela, a conquista do

\footnotetext{
23 PENHOS, Marta. Las fotografías del álbum de Encina, Moreno y Cía (1883) y la construcción de la Patagonia como espacio geográfico y paisaje. Huellas - dossier búsquedas em artes y diseño, n. 9, 2016, p. 65-80.
} 
"sertão" da Bahia pelo Império, não teria se concretizado. ${ }^{24} \mathrm{~A}$ imagem da conquista de Bendegó é a da conquista do território pelo império.

Vista como parte do conjunto de imagens que acompanhavam o relatório da expedição do Bendegó, esta fotografia parece ocupar um lugar importante. Ela demarca o momento em que a operação para elevação do meteorito do solo tinha terminado. O trabalho deve ter sido árduo, pois o meteorito estava dentro do rio Bendegó. Começaria então uma nova etapa: a colocação da pedra no carretão projetado especialmente para ela, e o início da marcha em direção à estrada de ferro.

Sabe-se que quando chegou à corte, o meteorito foi visitado por diversas autoridades: a princesa Isabel esteve no arsenal pelo menos três vezes ${ }^{25}$. Seu marido, o conde D’Eu, também “visitou” a pedra pelo menos uma vez, assim como os monarcas. Ainda não encontrei fotografias destes eventos, mas é difícil de acreditar que os membros da família real não tenham se deixado fotografar nesse contexto. Seria a estrutura dessas fotos parecida com " $15^{\circ}$ dia de trabalho", com os representantes do império ao lado, ou próximos do meteorito?

Pode-se ir um pouco mais além na investigação sobre esta fotografia. Se, como observou Rosalind Krauss, é preciso levar em conta as instâncias de difusão para compreender os "espaços discursivos" da fotografia, "15 dia de trabalho" parece ter circulado mais do que as outras imagens do álbum da expedição ${ }^{26}$. Além de ter sido colocada no álbum da expedição, há vários indícios de que ela seja uma das duas fotografias expostas na redação de O Paiz em 20 de agosto de 1887. Neste ponto, vale retomar alguns aspectos que já foram observados aqui. O caráter explicitamente posado dessa imagem-note-se novamente a indumentária lustrosa dos engenheiros, o posicionamento estudado dos grupos de trabalhadores - sugere que ela foi feita com um intuito de ser mostrada para um público mais amplo. E talvez não seja exagerado supor que ela foi concebida para ser uma espécie de cartão-postal, imagem-síntese do êxito "científico" alcançado pelo império. A assinatura do fotógrafo- o engenheiro Humberto Saraiva Antunes - colocada no canto direito da imagem reforça esta hipótese. O meteorito, os engenheiros e a bandeira compõem todo um discurso que associa a ciência ao Império, tornando a imagem perfeita para ser exposta em estabelecimentos da corte e, quem sabe, ser enviada para instituições de pesquisa e autoridades internacionais.

\footnotetext{
${ }^{24}$ E aqui é impossível não lembrar de Mary Louise Pratt, que apontou a importância de "ver", das imagens, verbais e visuais, na construção dos impérios e das relações desiguais entre as sociedades do globo a partir de fins do século XVIII. "In the end, the act of discovery itself, for which all the untold lives were sacrificed and miseries endured, consisted of what in European culture counts as purely passive experience - that of seeing." PRATT, Mary-Louise. Imperial Eyes, London: Routledge, p. $202-204$.

${ }^{25} \mathrm{Na}$ coleção Teresa Cristina, na Biblioteca Nacional existem duas fotografias do Bendegó que pertenceram à princesa Isabel. Alguns historiadores mencionam que a princesa teria ido ao porto "receber" o meteorito quando de sua chegada à corte.

${ }^{26}$ KRAUSS, Rosalind E; DAVÉE, Anne Marie, O fotográfico, Barcelona: Editorial Gustavo Gili, 2002.
} 


\section{O Bendegó nos jornais e a crítica de Machado de Assis}

Certamente essa associação entre o Estado Imperial e o meteorito do Bendegó foi passou despercebida pelos contemporâneos. A Revista llustrada usaria o meteorito em um uma charge de fundas reverberações na vida política e social da cidade. Nas imagens publicadas em página dupla, acompanhadas por legendas, Angelo Agostini sintetizava os debates suscitados pela lei de 13 de maio [Figura 3]. Em uma das primeiras cenas, o Bendegó, sobre o carretão, é observado pelo Barão de Cotegipe no Arsenal da Marinha. A seguir, em outro desenho, a enorme pedra é arrastada por um grupo de homens. Nas cenas seguintes, percebe-se que estes homens são o Barão de Cotegipe e seus apoiadores. Representados seminus, são mostrados como indígenas, mas de um jeito um tanto ridículo, já que seus traços fisionômicos, óculos, barbas etc., perfeitamente reconhecíveis, aparecem decorados com cocares, colares, tangas, arcos e flechas. A enorme pedra que carregam, traz, em letras garrafais, a palavra “indenização". Na cena central, uma grande locomotiva, com os dizeres "Lei de Treze de Maio de 1888", se projeta em direção ao primeiro plano, fazendo fugir, esbaforidos, os indígenas. À esquerda, três homens se comprimem sobre uma elevação de terra. Entre eles, podemos reconhecer Cotegipe e um outro homem, que aparece com as nádegas à mostra, que parece ser $\mathrm{d}$. Pedro II. Do outro lado, cinco homens parecem estar caindo, com a enorme pedra da Indenização e suas flechas espalhadas ao redor.

A Revista llustrada defendia ideias republicanas e abolicionistas, criando imagens sempre jocosas do império e de Pedro II. Vale a pena, assim, comentarmos brevemente a respeito dos personagens representados ali. Fiel até o fim aos interesses senhoriais, o barão de Cotegipe liderou o diminuto grupo de senadores que votou contra a Lei Áurea. Segundo alguns historiadores, o barão teria contado apenas com o apoio de apenas cinco outros senadores. Talvez sejam esses os homens que aparecem no canto direito da página. A palavra indenização, marcada na pedra, talvez seja referência à Lei dos Sexagenários, chamada Lei Saraiva-Cotegipe, que condicionava a alforria à indenização aos proprietários dos escravizados. Houve pedidos semelhantes no contexto das discussões a respeito da abolição, mas os donos de escravos não foram atendidos. Em oposição a este núcleo de personagens está justamente a locomotiva, dirigida por ]oão Alfredo Correia de Oliveira, político que fora nomeado no lugar de Cotegipe, para liderar o ministério que por fim encampou o projeto da abolição (chamado "Ministério 10 de março"). 


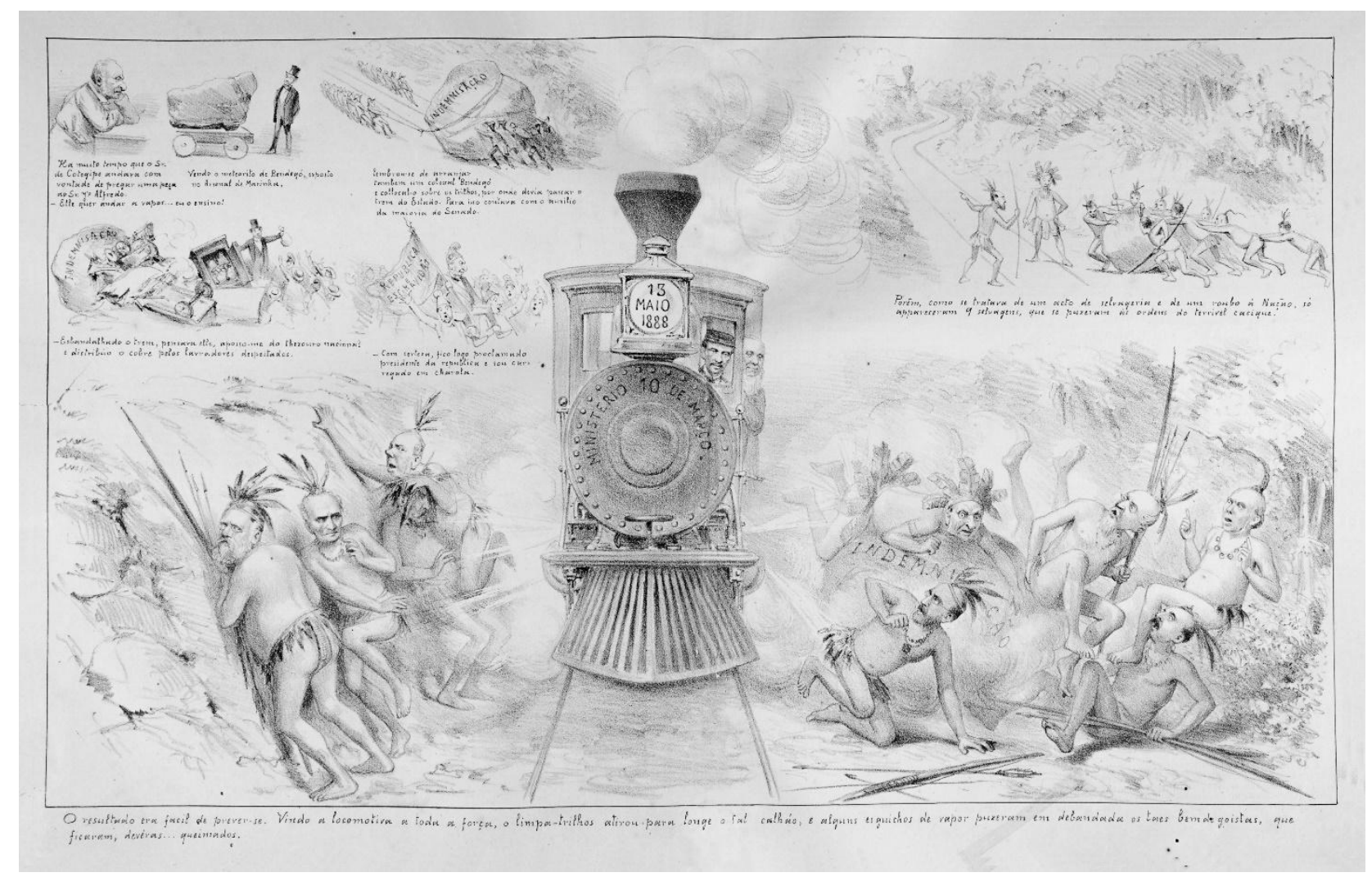

Figura 3:

Angelo Agostini, 13 de maio de 1888. Revista Ilustrada, Rio de Janeiro: ano 13, n. 506, 1888, p.4-5. Fundação Casa de Rui Barbosa.

Disponível em: http://www.memoriaescravidao.rb.gov.br/revista_ilustrada.php?pg=12. Acesso em: 20 mar. 2021.

Além da rica leitura do contexto político da abolição, a charge nos permite compreender como alguns contemporâneos - Angelo Agostini, e talvez muitos de seus leitores - compreendiam a função do meteorito nos planos do Império. E é justamente por isso que ele é representado entre os personagens. $\mathrm{O}$ Bendegó aparece associado ao Império, e ao que ele significava em 1888 para alguns: a escravidão e a barbárie. Significativo, nesse sentido, é que os defensores da escravidão estejam representados como indígenas. O indianismo romântico era coisa do passado. Num momento em que havia enorme esforço de mapeamento e domínio das comunidades originárias, em que o esforço civilizatório passava por mais uma etapa na dominação/destruição de grupos indígenas, o índio evocava o atraso, o "antigo"27.

\footnotetext{
${ }^{27}$ A partir dos anos 1870, muitas expedições são organizadas pelos “sertões" do Império. A Comissão Geológica do Império faria, por exemplo, extenso trabalho de mapeamento de grupos tradicionais. As fotografias feitas por Marc Ferrez seriam levadas para a Exposição Universal da Filadélfia, em 1876. A Sociedade de Geografia do Rio de Janeiro, não por acaso sede institucional da Comissão do Bendegó, também promoveu e custeou dezenas de expedições em que interesses geográficos, geológicos e "etnográficos" se combinavam. Sobre a Sociedade, ver por exemplo: CARDOSO, L. Sociedade de Geografia do Rio de Janeiro: identidade e espaço nacional (1883-1909) Dissertação (Mestrado em História) - Universidade do Estado do Rio de Janeiro, 2003. A Exposição Antropológica, organizada pelo Museu Nacional com os frutos de tantas expedições, acontece em 1882.
} 
A abolição avança sobre a nação como uma locomotiva - um dos símbolos de progresso na época. Já os proprietários de terras são representados como desengonçados e incivilizados índios, chamados na última legenda de "bendegoístas". ${ }^{28}$

Visão semelhante iria perpassar a arguta crônica de Machado de Assis no jornal Gazeta de Notícias. Publicado em 27 de maio de 1888, o texto narrava uma conversa entre o meteorito e o engenheiro Carvalho. A crônica já começava carregada de ironia:

Cumpre não perder de vista o meteorólito de Bendegó. Enquanto toda a nação bailava e cantava, delirante de prazer pela grande lei da abolição, o meteorólito de Bendegó vinha andando, vagaroso, silencioso e científico, ao lado do Carvalho. ${ }^{29}$

Machado chama a atenção para duas temporalidades: a do meteorito, que é levado da Bahia ao Rio de Janeiro, penosamente arrastado por bois, homens e trens, num trabalho de meses dentro do sertão. E aquela da nação, que, no centro do império, era sacudida por mudanças importantes. Em oposição às agitações da corte estava o meteorito, "vagaroso, silencioso e científico". A partir dessa introdução, o autor transforma o meteorito num crítico das ideias políticas em voga. Machado continua:

(...) andam por aí ideias republicanas, e que há certas pessoas para quem o advento da república é certíssimo. [O engenheiro] Chegou a ler-lhe um artigo da Gazeta Nacional, em que se dizia que, se ela já estivesse estabelecida, acabada estaria há muitos anos a escravidão.

O meteorito, espantado, lembra ao engenheiro que antes de ser meteorito fora general nos Estados Unidos - "e general do Sul, por ocasião da guerra da secessão". E complementa que a república americana começara justamente proclamando a manutenção da escravidão. Ao que o engenheiro responde, encerrando a discussão: "Mas é porque lá falam inglês". O meteorito resolve mudar de assunto, "cada vez mais vagaroso e científico." E assim termina a crônica.

O pequeno texto de Machado colocava em relação os dois grandes problemas da vida social e política naqueles dias: a abolição e a República. A abolição da escravidão, de fato, ocorrera dias antes, em 13 de maio. E a República, como sintetiza de modo arguto o cronista, seria implementada, por golpe, no ano seguinte. Nesse cenário de grandes mudanças, o meteorito passava alheio, como ironiza Machado de

\footnotetext{
${ }^{28}$ Interessante observar que as escolhas do chargista sintetizam os termos em que a abolição é realizada no Brasil: a lei foi peça no esforço do país em se "modernizar", mas não estava atrelada a projetos de melhoria social e econômica para os exescravizados. Ou seja, na prática a lei áurea manteve intactas as hierarquias sócio-raciais que remontavam ao período colonial. ${ }^{29}$ ASSIS, Machado de. Bons dias. Gazeta de Notícias, Rio de Janeiro, 27 mai. 1888.
} 
Assis, "vagaroso e científico". ${ }^{30}$ Com grande sagacidade, Machado reconhece que o meteorito já chegara "antigo" ao Rio de Janeiro. Seu tempo era outro - aquele da escravidão e do império.

A observação de Machado, de fato, se coaduna com um aspecto importante das fotos da expedição, que ainda não foi discutido em pesquisas sobre a história do meteorito, ou do Museu Nacional: as imagens admitem muitas aproximações com imagens dos escravizados, feitas em fazendas de café ou em pequenos povoados. Ao fazer comparações como essas, um dos objetivos dessa pesquisa é situar o fazer científico do Império dentro de seu contexto mais amplo, e inescapável: aquele da escravidão e da desigualdade social, que seria mantida nos tempos republicanos.

\section{Ciência e violência nas imagens do Bendegó}

Quando se analisa o conjunto de fotografias que acompanha o relatório, verifica-se que o meteorito não é o objeto principal. Ele acaba sendo quase uma desculpa, um instrumento para mostrar o verdadeiro tema das imagens: o trabalho da Comissão para dominar a natureza "original". Trazer aquela massa pesada do meio do sertão para o museu foi uma tarefa muito complexa, tanto do ponto de vista técnico como humano. O verdadeiro tema das imagens, portanto, era este: mostrar a grande façanha dos engenheiros: arrancar o meteorito da natureza.

Nesse ponto, vale a pena retornar às fotos da comissão Bendegó. Elas estabelecem mais uma etapa da apropriação simbólica do território pelo império. Dessa forma, mostram um Brasil em processo de "civilização".

Não pude saber, até agora, se havia escravizados entre aqueles homens. O relatório da Comissão do Bendegó guarda um silêncio “interessado" sobre esta questão. No entanto, outro relato sobre a expedição do Bendegó, este escrito por Orville Derby, tem um pequeno trecho que ajuda a esclarecer a questão. Em artigo publicado nos Anais do Museu Nacional, Derby discorre sobre o carretão que transportou a massa sideral:

Cada eixo tinha um par de rodas largas e maciças de madeira para rodar no solo, e também um par interno de rodas ferroviárias, ligeiramente menores em diâmetro, ajustadas de forma que, quando colocadas sobre trilhos, as rodas externas ficassem suspensas. ${ }^{31}$

Em encostas íngremes e terreno defeituoso eles usaram os trilhos, Derby completou, "o carro sendo puxado por homens, ou bois, (....." Homens ou bois. A frase curta de Derby fornece um sentido um tanto

\footnotetext{
30 Ibidem.

${ }^{31}$ DERBY, Orville A. Estudo sobre o Meteorito de Bendegó. Archivos do Museu Nacional, v. 9. Rio de Janeiro: Museu Nacional, 1895, p.98-99.
} 
dramático para as imagens da Comissão do Bendegó. A começar pelo fato de que os bois aparecem apenas nas duas primeiras imagens do relatório. Essas fotografias mostram a saída do grupo do sertão, após a retirada da pedra do rio Bendegó. Contudo, logo o caminho seguido pela comissão mostrou-se cheio de desafios: incluía passar por montanhas e serras, áreas estreitas, com muitas árvores, ou completamente acidentadas e alagadas. Terrenos que os bois, muitas vezes, não conseguiam atravessar. Nesses locais, como atestam as imagens, o trabalho foi feito por homens.

Ao observar essas as imagens, percebemos muitas aproximações com as fotografias de escravizados. As primeiras imagens desse tipo que circularam no Rio de Janeiro aparecem no álbum O Brasil Pitoresco (1861), de Charles Ribeyrolles e Victor Frond. As litografias, feitas a partir das fotografias de Frond, mostravam cenas de trabalho, tanto na cidade quanto nas fazendas, onde os escravizados eram os protagonistas, saindo para trabalhar na roça, moendo cana ou descascando mandioca ${ }^{32}$. Talvez por isso as imagens tenham se tornado muito mais conhecidas do que o texto de Ribeyrolles, sendo republicadas várias vezes ao longo do século. $\mathrm{Na}$ "Exposição de História do Brasil" organizada pela Biblioteca Nacional em 1881, foram expostas várias litografias de O Brasil Pitoresco. Talvez nesta ocasião o fotógrafo Marc Ferrez tenha visto Partida para Roça [Figura 4] de Frond. Sua Saída para a Partida para a colheita do café com carro de bois (1885) tem vários aspectos em comum com a imagem feita por Frond. Em ambas, os capatazes eram representados separadamente dos escravos, de modo a explicitar relações de poder e subordinação.

O fotógrafo que acompanhou a encomenda de Bendegó certamente conhecia essas imagens. Passagem no terrro do Rio Jacuricy, Passagem no alto da Serra do Acaru, Passagem do meteorito no Rio Jacuricy, entre outras imagens, seguem uma estrutura semelhante. Porém, se Frond e Ferrez buscam representar um grupo de escravizados na paisagem, o fotógrafo da Comissão do Bendegó tem interesses mais específicos. Ele quer dar destaque aos engenheiros e, claro, à grande massa sideral colocada entre os trabalhadores. Os engenheiros sempre aparecem apartados dos demais, para demarcar sua posição social. Por isso, o fotógrafo de Bendegó evita a visão panorâmica da paisagem, presente nas imagens de Frond e principalmente de Ferrez. Faz recortes mais restritos. Seu interesse é mostrar os personagens - com destaque para os engenheiros, facilmente destacados do resto-e o meteorito.

As imagens dos Bendegó mostram a técnica e o controle do território. Mas elas também representam a desigualdade. Em imagens coletivas, como Passagem do Meteorito no Rio Jacuricy [Figura 5], trabalho e hierarquia social são encenados e representados.

\footnotetext{
${ }^{32}$ SILVA, Maria Antonia Couto da. As relações entre pintura e fotografia no Brasil do Século XIX: considerações acerva do álbum Brasil Pitoresco de Charles Ribeyrolles e Victor Frond. Fênix-Revista de História e Estudos Culturais, v. 4, n. 2, jun. 2007 , p. 1-18.
} 


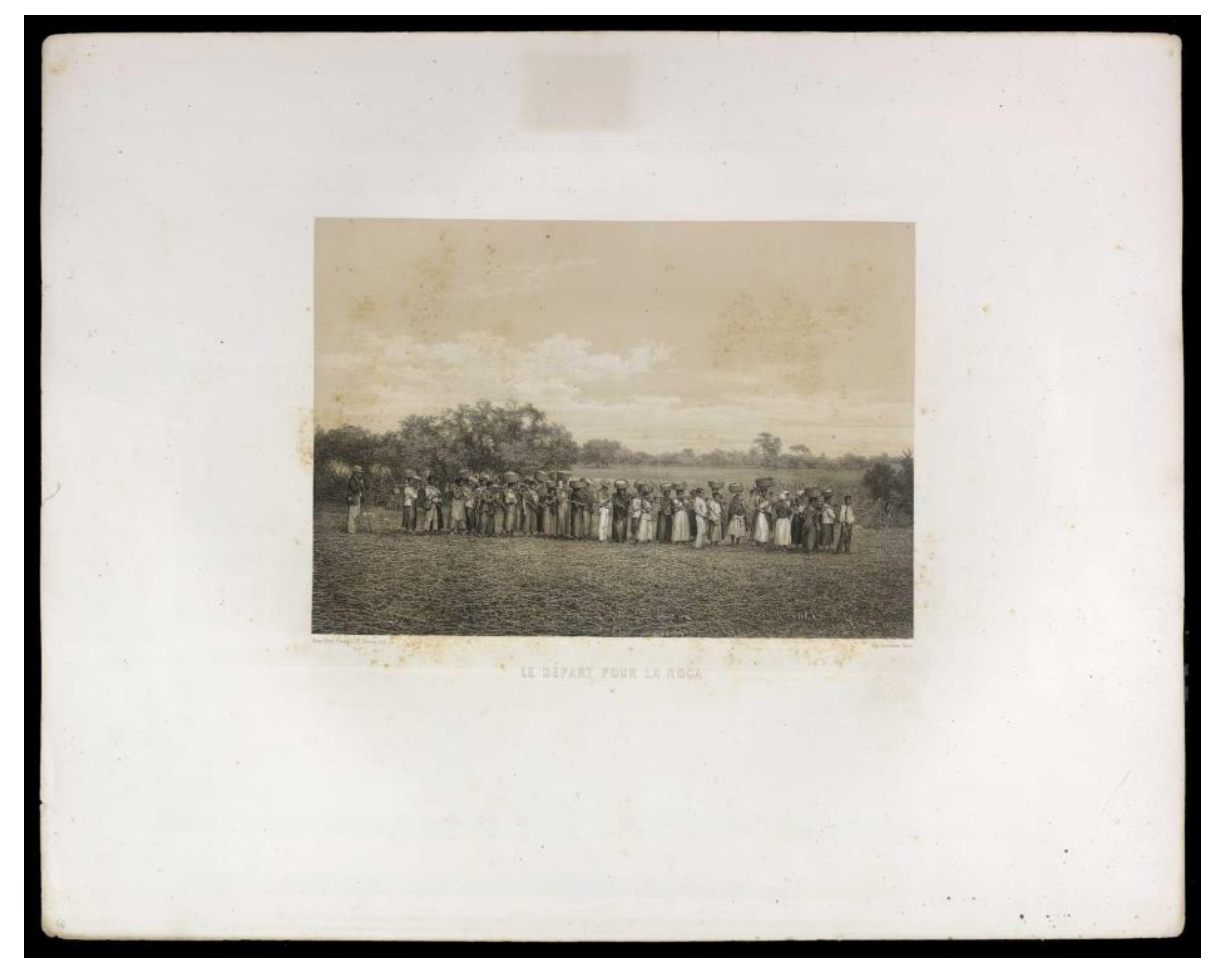

Figura 4:

Victor Frond, Partida para Roça. In: Charles Ribeyrolles e Jean-Victor Frond. O Brasil Pitoresco, Rio de Janeiro, Tipografia Nacional, 1861. Biblioteca Nacional - acervo digital. Disponível em: http://objdigital.bn.br/objdigital2/acervo_digital/div_iconografia/icon1113654/icon1113654_52.jpg. Acesso em:

20 mar. 2021

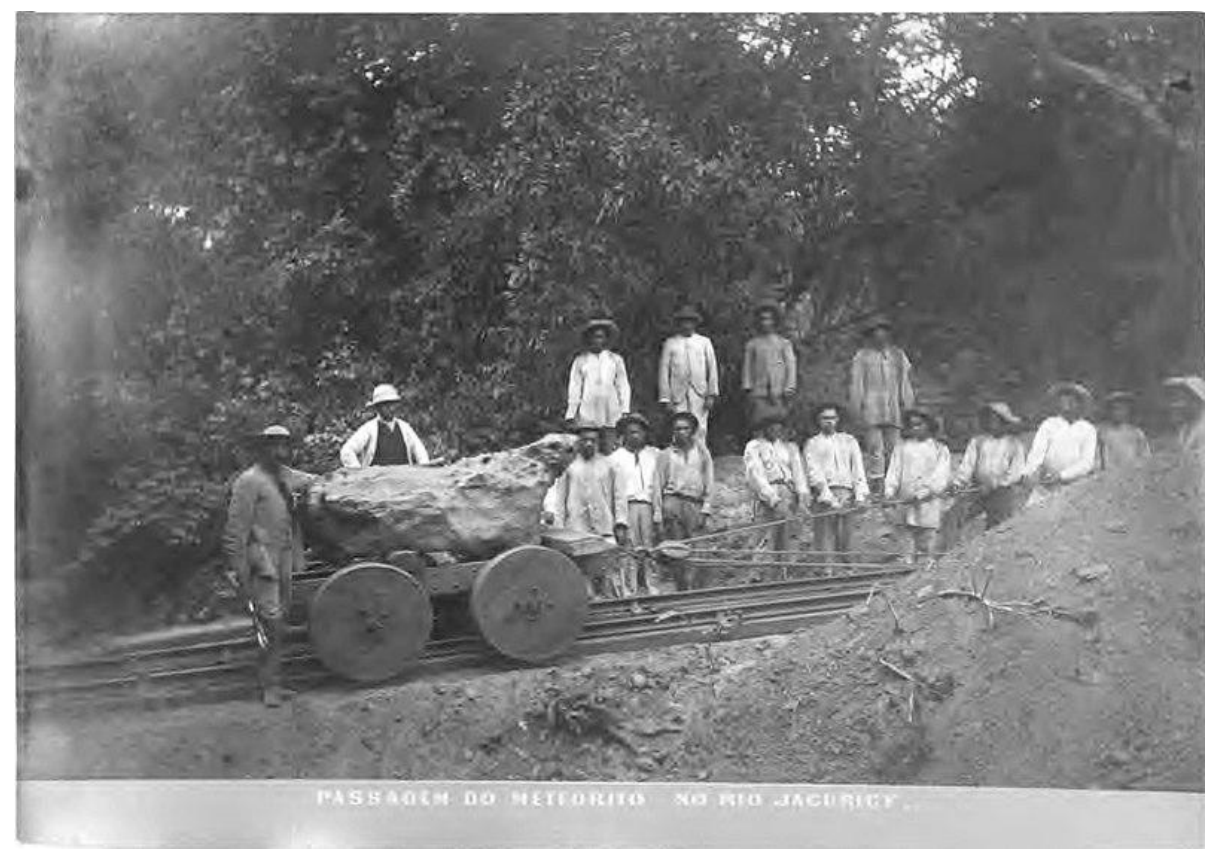

Figura 5:

Passagem no aterro do rio Jacuricy. In: Meteorito de Bendegó - relatório apresentado ao ministério da agricultura, commercio e obras publicas e a sociedade de geographia do Rio de Janeiro sobre a remoção do meteorito de Bendengó do sertão da provincia da Bahia para o Museu Nacional. Rio de Janeiro: Imprensa

Nacional, 1888. Universidade Federal do Rio de Janeiro. Disponível em: https://bdor.sibi.ufrj.br/bitstream/doc/32/1/bendego-port\%20ocr.pdf Acesso em: 20 mar. 2021. 
$\mathrm{Na}$ frente, sempre um ou mais engenheiros. Eles se destacam facilmente dos demais: estão sempre separados de grupos maiores, geralmente colocados mais próximos do fotógrafo. Usam botas de montaria e têm uma postura confiante.

As imagens da Comissão do Bendegó tratam, assim, dos milagres da engenharia: os engenheiros aparecem elegantes e orgulhosos. Atrás deles, malvestidos - calças encurtadas, blusas sujas e rasgadas, os trabalhadores aparecem na tarefa diária de arrastar aquela enorme pedra. Eles não têm rostos. Suas feições - suas características raciais - não podiam ser percebidas nas imagens originais. As imagens de Bendegó promovem, também, uma espécie de branqueamento da comissão. As características raciais do grupo não são explicitadas. Os trabalhadores não têm raça, identidade ou história. Eles fazem parte do cenário selvagem, às vezes pedregoso, às vezes arborizado, do entorno.

No afã de delimitar o que era considerado civilizado, ou "científico" - o meteorito, e o feito dos engenheiros de arrancá-lo do sertão, delineava-se também o que estava fora desse domínio- o que era bárbaro, "primitivo", não civilizado. No caso do Brasil do século XIX, esse processo tem traços ainda mais trágicos, por causa da escravidão. Nesse contexto, a ciência era atributo dos cidadãos do Império homens, brancos, ricos e letrados. Desde a independência, todo o resto da população ficava de fora.

As imagens veiculadas na imprensa da época, amplamente reproduzidas em sites e blogs até hoje, trazem assim um fato paralelo: a violência. Violência dos corpos que se dobram no trabalho que deveria ser de animais de carga. Violência da falta de identidade. As fotografias da comissão, desse ponto de vista, expressam, ainda que de forma não programada, relações de trabalho típicas da sociedade com passado escravista e nada "civilizado" do império. A violência aparece, assim, como aspecto que articula ciência e política nas imagens da Comissão do Bendegó.

\section{Agradecimentos:}

Este artigo é uma versão ampliada de artigo publicado em Anuario Tarea. Revista De Estudios Sobre El Patrimonio Cultural, n.7, 2020. Agradeço à Fundação de Apoio à Pesquisa do Estado de São Paulo, a FAPESP, pelo auxílio-pesquisa recebido, que tem contado com a participação da bolsista Mayara Silva Dantas no levantamento e sistematização dos dados. 